\title{
Coro Cênico: Conceito e Discussões
}

\author{
Scenic Chorus: Concept and Discussions
}

por Cristiane Muller e Luiz Henrique Fiaminghi

RESUMO

0 panorama da música coral no Brasil passou por uma renovação a partir da década de 1960. Além de ter sido construído um vasto repertório de música popular em arranjos para coros, destacaram-se nomes importantes que atuaram como compositores, arranjadores e/ ou regentes e estabeleceram novos parâmetros para performance vocal em grupo, surgindo o termo Coro Cênico. Os objetivos deste trabalho são levantar uma discussão sobre a definição e aplicação do conceito de Coro Cênico, na perspectiva de um trabalho coral que procura a integração com outras artes como o teatro e a dança e identificar o uso de uma técnica diferenciada do cantor de Coro Cênico. Enquanto alguns autores acreditam que todo o coro é cênico, outros argumentam que nem todo o Coro Cênico é verdadeiramente cênico. Dentro desta nova modalidade coral é de fundamental importância desenvolver uma técnica vocal ampliada, não voltada unicamente para a projeção e homogeneidade sonora, aliada à conscientização interpretativa do cantor e à variedade do repertório, bem como à utilização de jogos teatrais que visam a uma maior presença cênica. Neste sentido, a neutralidade dos cantores no palco é quebrada, fugindo dos padrões tradicionais pré-estabelecidos.

Palavras-Chave: Coro Cênico; Artes Integradas; Canto coral

\section{ABSTRACT}

Choral music's landscape in Brazil has gone through a renovation as of the sixties. Besides the fact that a vast repertory of popular music in arrangements for choir was built, some important names that acted as composers and arrangers and/or conductors stood out and established new parameters for vocal performance in group, giving rise to the term Scenic Choir. The aims of this article will raise a discussion about the definition and application of the concept Scenic Choir, from the perspective of a choir work which seeks the integration with other types of art such as theater and dance and identify the use of a differentiated technique of the Scenic Choir singer. Whilst some authors believe that every choir is scenic, others reason that not every Scenic Choir is truly scenic. Within this new choir modality, it is very important to develop an enlarged vocal technique, not geared only to homogeneous and projection sound, allied to the singer's interpretive awareness and to the variety of repertory, as well as to the use of theater games aimed at a greater scenic presence. In this sense, the neutrality of the singers on stage is broken, fleeing the traditional, established standards.

Keywords: Scenic Choir; Integrated Arts; Choral singing 


\section{Coro Cênico: Conceito e Discussões}

\section{Introdução}

0 presente artigo surge da pesquisa de mestrado que trata sobre o Coro Cênico iniciado em 2012. A partir do histórico levantado desde o movimento do Canto Orfeônico, passando por grupos vocais e corais de variadas formações ocorridas durante o século XX no Brasil, a pesquisa busca finalizar sua trajetória revelando ao leitor sobre grupos no Sul do Brasil que atualmente estão desenvolvendo o canto em grupo aliado a outras artes como o teatro e a dança. Toda a efervescência histórica destas artes que vieram caminhando cada vez mais unidas culminou em múltiplos modelos de coro que podem ser vistos em diversas regiões brasileiras.

0 processo de criação e sistematização do Coro Cênico no Brasil tem sido amplamente desenvolvido dentro de grupos brasileiros formados desde a década de 60. Segundo Zanatta (2008, p.3), uma nova abordagem do canto coral tem sido empregada por um maior número de grupos que utilizam voz, corpo e movimento na "construção da expressividade artístico musical". Por sua vez, Oliveira cita duas modalidades importantes que surgem neste processo, e afirma que ambas envolvem a questão do "hibridismo de linguagens". Tanto a canção de massa como os vários movimentos artísticos que nortearam a década de 60 acabaram propiciando a formação do Coro Cênico na modalidade "[...] "vanguardista", que surge sob a égide do Movimento Concretista e a modalidade "cancionista", provinda da música popular" (OLIVEIRA, 1999, p. 13).

Por iniciativa da Secretaria Estadual de Cultura de São Paulo e do Coro Cênico Bossa Nossa (direção musical de Adriane Biagini e a direção cênica de Magno Bucci), é possível conhecer e vivenciar esta modalidade de canto coral que vem sendo difundida em diversas cidades do país. Em 2007 o Coro Cênico Bossa Nossa (BOSSA NOSSA, s/a, histórico) organizou o I Encontro Brasileiro de Coro Cênico que teve como sede a cidade de Ribeirão Preto, em São Paulo. 0 evento que já está na sua quinta edição, realizada em 2011 na mesma cidade, também é sede de debates sobre o movimento de Coro Cênico no Brasil.

A ideia surgiu a partir da constatação de que o Brasil produz um trabalho com corais que difere da ideia comum de coro, onde se imagina uma série de pessoas vestidas, com vestes próprias de corais formais, portando pastas com as partituras e normalmente estáticas (V Encontro Brasileiro de Coro Cênico, 2011, s/p).

A partir de dados levantados por adeptos do coro cênico, a revista eletrônica Revide (2011, s/p) conta que "existem no Brasil cerca de 30 grupos que desenvolvem esse trabalho musical e cênico em sincronismo". Conforme Odônio dos Anjos (REVIDE, 2011, $s / p$ ), organizador do encontro e integrante do Coro Cênico Bossa Nossa, o evento aliou discussões às apresentações já que é na prática que podemos ver como "esta combinação pode dar certo". As discussões e reflexões buscaram avaliar as propostas dos grupos, houve a troca de experiências de seus processos criativos e dos precursores do movimento que fizeram parte do evento. 


\section{Coro Cênico: Conceito e Discussões}

O V Encontro Brasileiro de Coro Cênico' teve a presença dos profissionais considerados os precursores deste movimento: Samuel Kerr, Izaíra Silvino e Patrícia Costa (representando Marcos Leite). Fizeram parte das discussões outros debatedores, a saber, o maestro italiano Antonio Pantaneschi, Celso Branco, a regente Claudia Mussi, o regente Luiz Carlos Prata, os diretores cênicos Magno Bucci e Zedú Neves.

Celso Branco, pesquisador em história da música, arranjador do grupo do "Os Men the Sá" e um dos debatedores do painel, lembra que o coro cênico surgiu nos anos 70 e 80, quando dois maestros-Samuel Kerr e Marcos Leite se destacaram no cenário nacional por incluírem linguagens cênicas nas apresentações dos corais (OVERMUND0, 2011, s/p).

A partir daí outros corais passaram a apresentar propostas semelhantes e atualmente os mesmos se aproximam da linguagem teatral com performances variadas. Para Celso Branco, quando se mistura teatro com música, o artista só tem a ganhar: "A linguagem cênica auxilia na comunicação do artista com a plateia". A proposta de discussão que ocorreu no evento incluiu a conjuntura e as dificuldades dos corais em desenvolverem a linguagem cênica e possíveis soluções para as mesmas. Ao longo dos anos, diversos grupos já participaram do Encontro Brasileiro de Coro Cênico, e a última edição do evento foi no ano de 2011 com a presença dos grupos Coro Cênico Bossa Nossa (Ribeirão Preto/SP) anfitrião do evento; Coro Cênico Ciranda da Arte (Goiânia/Go); Coral Jovem Cênico Mackenzie (São Paulo/SP); Os Men the Sá (Rio de Janeiro/RJ) e o Grupo Vocal Laugi (Braília/DF).

Constatando que o movimento de Coro Cênico está presente em diferentes regiões brasileiras, trago para o artigo uma discussão sobre o conceito desta expressão tão utilizada pelos grupos e que dá título para oficinas de canto coral realizadas em festivais de música no Brasil. Além da bibliografia já existente conceitos e visões sobre a expressão em questão, apresento um breve resultado do questionário² realizado com três regentes que atuam nesta modalidade com seus grupos: Vicente Ribeiro, regente do grupo Vocal Brasileirão (Curitiba/PR); Pablo Trindade, regente do Expresso 25 (Porto Alegre/RS) e Sérgio Oliveira, regente do Coral da USP (Ribeirão Preto/SP).

\section{Conceito E Discussões}

A expressão "Coro Cênico" é um conceito aceito por alguns especialistas na área de regência e "detestado" por outros. Sua definição e aplicação para representar o trabalho coral integrado com outras artes como o teatro e a dança é problemática e está tratada aqui sob diversas perspectivas. No artigo "Coro Cênico: breves reflexões a partir de uma prática", Magno Bucci, diretor cênico do Coro Cênico Bossa Nossa, comenta que "Coro Cênico é uma noção em processo de elaboração, uma definição em progresso, uma ideia que arrisca conceituações" (2007, p. 1). 0 autor afirma em outro artigo intitulado

10 evento é uma iniciativa do Coro Cênico Bossa Nossa, de Ribeirão Preto, e da Secretaria Estadual de Cultura de São Paulo, através de edital do ProAC, com apoio da ONG Cineclube Cauim e Cineclube Canarinho.

20 questionário faz parte da dissertação de mestrado que será finalizada no ano de 2013. 


\section{Coro Cênico: Conceito e Discussões}

"Nem todo coro é cênico e nem todo "Coro Cênico" é cênico", que a expressão Coro Cênico é uma modalidade do canto coral. Bucci (2010, p. 1) cita os arranjadores e regentes Marcos Leite e Samuel Kerr como dois dos maiores nomes da renovação do canto coral no Brasil: "Leite e Kerr, entre outros de percepção apurada e visão prospectiva, a partir da década de 60 ampliaram as possibilidades da música coral".

Marcos Leite é unanimidade. 0 maestro e uma plêiade de "cúmplices", além de seguidores, marcaram de maneira inquestionável a atividade coralistica em nossas terras. 0 trabalho desses "quixotes" - além de ter eletrizado e contaminado aqueles que, direta ou indiretamente viram os resultados de suas "ousadias" - fez história. É referência. Citação obrigatória em qualquer inventário musical coralista (BUCCl, 2010, p.1).

Bucci marca como divisor de águas o trabalho de Marcos Leite com o seu grupo coral da Cultura Inglesa na apresentação realizada no Festival de MPB Shell de 1981, que ganhou o prêmio de "Melhor Trabalho Criativo do MPB Shell 81" com a canção Cobras $O$ Lagartos $^{3}$, composição e arranjo de Nestor de Hollanda Cavalcanti, parceiro de Marcos Leite por vários anos, neste e em outros trabalhos.

0 impacto causado pela apresentação de Cobras at Lagartos, no Festival, teve repercussão em todos os cantos. Uma febre tomou conta de grupos corais, muitos querendo seguir as mesmas pegadas: pedidos de oficinas, cursos, apresentações. Uma efervescência. 0 Cultura Inglesa, com aquele trabalho, materializava o sonho e o desejo de muitos coralistas, sinalizava que o novo chegara. Ventos inaugurais voltavam a inflar a música coral (BUCCl, 2010, p.1).

Alguns grupos têm uma abordagem de trabalho coral que faz um contraponto entre 0 coro tradicional, onde a execução musical é muitas vezes a única preocupação, e o coro cênico, onde o teatro pode assumir um patamar de igual importância ao da música. Os cantores têm maior liberdade de movimentos (apesar de serem dirigidos cenicamente), os quais surgem a partir da interpretação musical. Bucci (2007, p. 3) apresenta uma discussão sobre o trabalho cênico dentro dos grupos corais, afirmando que "não basta estar no palco para que esta manifestação seja cênica".

Não é pelo simples fato de se estar no espaço de representação que qualquer manifestação é cênica. Não bastam noções de marcação no espaço cênico para que a atividade seja assim considerada. Não se pode atribuir a classificação "cênica" à movimentação no palco - ou em qualquer espaço tornado cênico - que ostente um figurino ou se utiliza de equipamentos técnicos disponíveis. Essas explicitações do cênico são equivocadas. Contra interpretações dessa natureza opõe-se o peso da história do teatro (BUCCl, 2007, p. 3).

Em contraposição Marcos Leite, importante modelo e estímulo no surgimento de um número expressivo de arranjadores e grupos vocais, afirmou em uma entrevista para a monografia de especialização de Kohler, que todo o movimento que o coro faz, por

3 Ver vídeo Cobras U Lagartos em referências. 


\section{Coro Cênico: Conceito e Discussões}

mais tradicional que seja, é cênico, pois está em cena, e acreditava que devêssemos rever esta definição.

-Coro cênico? É hum... é hum...bom, pra começar, detesto essa expressão, coro cênico, né. Porque é uma expressão redundante, pleonástica, né. Qualquer coro é cênico, né. Se você....hã se você entra em cena, bota o pé no palco, você tá em cena. Então você pode adotar uma postura cênica tradicional, ou adotar uma postura cênica não tradicional (LEITE em entrevista a KOHLER, 1997, p. 75).

Ao serem questionados sobre o conceito de Coro Cênico no questionário realizado pela autora para esta pesquisa pôde-se averiguar que os regentes Vicente Ribeiro e Pablo Trindade acreditam que "todo coro é cênico" (TRINDADE, informação verbal) e que "[...] qualquer apresentação musical realizada em um palco envolve, forçosamente, elementos cênicos: movimentação, figurino, cenário, iluminação..." (RIBEIRO, informação verbal). Ribeiro afirma que esta expressão é um "pleonasmo", já que sua conclusão também é de que "todo coro é cênico". Trindade complementa explicando que se um grupo coral estiver se apresentando para um público, ele estará utilizando um "espaço cênico" e comunicará sua música "sem poder se desvencilhar do seu corpo", por mais que tenha pouca ou muita consciência sobre ele: "Claro, se utiliza comumente a terminologia "coro cênico" para aquele grupo coral que além de cantar, se movimenta explicitamente, seja realizando coreografias ou se expressando teatralmente" (informação verbal) ${ }^{4}$. Sobre a discussão o regente Sérgio Oliveira elucida a questão trazendo outra expressão para explicar o conceito tão discutido: "Coro Cênico".

Coro Cênico é uma proto-linguagem ligada ao grande gênero Teatro-Musical. Proto porque ainda não é uma linguagem estabelecida, já que para isso necessita de muitos elementos, tais como prática, dramaturgia, composições, arranjos específicos, profissionais treinados e até mesmo cumprimento de legislação de direitos autorais, mas que tende a se estabelecer como uma linguagem com diferentes perfis: cancionista, vanguardista, funcionais (terapêutico, por exemplo), etc. (informação verbal) ${ }^{5}$.

A partir desta citação é necessário chamar atenção ao que diz respeito à consideração que o regente dá para esta expressão. Oliveira entende que ainda não temos um estabelecimento da linguagem, já que ela necessita de um amadurecimento de todos os elementos citados por ele. Além disso, o regente assegura que o "Coro Cênico" tem ligação com o Teatro Musical, e sabe-se que esta linguagem é bem resolvida em todas as direções artísticas como o canto, a dança, o teatro e as artes visuais num âmbito geral.

\section{As linguagens de apoio $X$ tradição coral}

Marcos Leite na entrevista concedida para Kohler afirma que grupos corais a partir dos

$4 \quad$ Pablo Trindade em resposta ao questionário para a presente pesquisa.

5 Sérgio Alberto de Oliveira em resposta ao questionário para a presente pesquisa. 


\section{Coro Cênico: Conceito e Discussões}

anos sessenta utilizaram linguagens de apoio como o teatro e a dança, trabalhando respectivamente com interpretação, figurino, iluminação e coreografia. Define a diferença do ator para o cantor: "-0 ator conta uma história pra plateia. 0 Cantor canta uma história pra plateia" (KOHLER, 1997, p. 78).

Bucci insiste em sua argumentação alegando que em muitos casos, existe somente um trabalho de "ilustração da canção". Isto seria "tomar a ação cênica como mero sinônimo de movimentos e atos apenas" (2007, p. 3). Ele acredita que se estas duas linguagens não forem trabalhadas de igual forma, "se o binômio música/teatro não for equacionado do ponto de vista teatral", dificilmente a essência do cênico será alcançada. Ele cita seu trabalho de direção cênica com o grupo Bossa Nossa e argumenta que o teatro e o canto coral compõem-se com "equivalências iguais, sem predomínio de uma sobre outra": "Para nós coro cênico é a imbricação de duas linguagens - uma hibridização" (BUCCl, 2007, p. 4). Para que um coro seja cênico então, o que seria indispensável? Oliveira entende que a integração da música com outras artes deve ocorrer para que 0 hibridismo aconteça sem que seja de forma amadora: "[...] é como cantar uma música cômica e os próprios coralistas ficarem rindo" (informação verbal) ${ }^{6}$.

Em entrevista concedida para a monografia de Kohler, Samuel Kerr, considerado por Marcos Leite e por muitos regentes e arranjadores como um dos pioneiros desta nova abordagem coral, faz um discurso revelador quando é questionado sobre o que ele entende e aceita por Coro Cênico:

\footnotetext{
-Nego, eu não entendo nada de coro cênico. Nada, nada. Eu, hã, sou apontado no... no mov... na história do canto coral, pelo menos em São Paulo, como o cara que inventou o coro cênico. Eu não inventei o coro cênico. Coro sempre foi cênico, não é? Só que, hã, como nós estamos falando de estereótipos, né, ou modelos inalcançáveis, a cena original do coro é completamente, hã, inadequada para os nossos padrões: pesadas togas, coros imobilizados em estrados bem construídos, numa acústica favorável, [...] essa cena era muito bonita e era suficiente (KERR em entrevista a KOHLER, 1997, p. 61).
}

Kerr prossegue sua fala expondo que essas condições no Brasil não eram nada favoráveis para o nosso clima e os locais não eram apropriados para este tipo de execução vocal. Então, ele resolve tirar a toga, colocar outra roupa no coro, questionar sobre a posição do coro, sobre o local aonde este grupo irá se apresentar, e tudo acaba trazendo uma consequência visual diferenciada:

-Quando você tira o coro do estrado, que é tão adequado pra projeção das vozes, você vai ter que colocar o coro em outra posição. Por que que você escolheu essa outra posição? Quando você vai fazer o coro cantar num lugar onde ninguém quer ouvi-lo, você vai inventar um jeito que as pessoas queiram ouvi-lo. Este jeito que as pessoas talvez queiram ouvir o coro vai determinar uma nova postura do coro. Coro é sempre cênico. Agora, um regente que tá preocupado com a função do coro, preocupado com o destino do coro, tá preocupado com a voz dos seus cantores, este coro tem uma consequência cênica (KERR em entrevista a KOHLER, 1997, p. 83).

$6 \quad$ Oliveira em resposta ao questionário para a presente pesquisa. 


\section{Coro Cênico: Conceito e Discussões}

Com este relato de Samuel Kerr e o que apresento a seguir, abriu-se uma nova percepção e uma hipótese: que este trabalho cênico não foi proposital, calculado e dimensionado. A história foi marchando a passos lentos, os grupos foram desenvolvendo novas táticas de execução, surgiram aos poucos ideias para resolver problemas de sonorização, de local de apresentação, de especificidade vocal dos grupos.

Nestor de Hollanda Cavalcanti, compositor e arranjador de inúmeras canções para os grupos de Marcos Leite, relata que em seu trabalho com o Cobra Coral e o Garganta Profunda, o fator que garantia sucesso dos arranjos era o som emitido, aliado à descontração e variedade de repertório. Estes grupos foram formados "sem opressões, sem limitações às individualidades, estimulando a criatividade sem ser programático". (CAVALCANTI, 2006, p. 113). Havia certo cuidado com a parte cênica, e mesmo sem a proposta de ser um "coro cênico", era necessária a presença de um diretor de cena, responsável pelo direcionamento do grupo em palco.

Cavalcanti também acredita que se a pessoa está em palco e exerce uma atividade artística, este indivíduo está em cena, cantando ou representando, e que sempre esse grupo terá a necessidade de um diretor cênico (que nos trabalhos de Marcos Leite, acabou sendo o próprio Cavalcanti). Um dos motivos pelo qual Cavalcanti terminou sendo o diretor cênico do grupo Garganta Profunda foi o fato de que surgiram problemas acústicos em um dos espaços cênicos aonde o grupo iria se apresentar. "Então, devido a esses problemas, era imprescindível descobrir posições específicas do coro em cena para cada música. E assim foi feito" (CAVALCANTI, 2006, p.83).

Entretanto, Cavalcanti (2006) conta que outro diretor havia participado inicialmente do trabalho, mas o grupo não o aceitou por ele cobrar determinadas situações dos cantores como se eles fossem atores, e esta não era a proposta do grupo. Percebe-se com estes relatos que inicialmente as mudanças no trabalho estético dos grupos para estas mudanças em questão não buscavam como finalidade desenvolver a linguagem teatral apropriadamente, a ponto de se igualar ao mesmo patamar e importância da música que era feita. Atualmente este objetivo tem recebido mais atenção dentro do trabalho coral.

\section{Os limites do Coro Cênico}

Bucci (2010, p. 4) continua sua defesa em relação à definição do que seria então um coro cênico, proferindo que não é somente por um grupo optar não permanecer na "versão clássica", "ilustrar a letra" ou "bailar" na canção e cantar "caminhando ou se movimentando uniformemente quando se apresenta", que este grupo pode ser chamado de coro cênico: "Nada em oposição às maneiras diferentes e divergentes de um coro estar em cena, [...] mas daí a ser considerado "cênico", do ponto de vista da arte teatral, há enorme distância".

0 diretor acredita que as experimentações cênicas, as "atitudes desbravadoras" dos grupos e seus regentes, "peripécias cênicas do coro" já tiveram seu tempo, e que atualmente os profissionais devem ter consciência e estar atentos para não repetirem 


\section{Coro Cênico: Conceito e Discussões}

os "modelos consagrados". Bucci percebe que atualmente existe o que ele chama de "hipertrofia do canto" e uma tendência de "alienação" para tudo o que diz respeito às especificidades do teatro, sem a "apropriação da linguagem com a qual se vai trabaIhar". Ele propõe uma "reconstrução da modalidade" com certo equilíbrio (casamento) entre as linguagens, procurando "estratégias de superação" com olhar atento ao que já foi produzido na história:

É mais que tempo de aprofundar outros conhecimentos e "revisitar" o território das artes integralizadas na criação do coro cênico. E a direção que me interessa seguir, indica que coro cênico seja entendido como: um grupo de pessoas que se reúne com o objetivo de produzir, expressar-se e comunicar-se através de um produto artístico híbrido que contempla duas linguagens: o canto coral e o teatro. Não estou propondo nada além do óbvio (BUCCl, 2010, p. 4-5).

Outra autora que trabalha com regência coral trata de questões diferenciadas para explanar sobre o trabalho com corais brasileiros da segunda metade do século XX: Camargo (2010, p. 5) não se apropria do termo Coro Cênico em sua dissertação e se utiliza de termos com características corais que ganharam força no decorrer dos anos após a década de 60. A saber, algumas citações: "o surgimento de uma nova poética de escrita coral", "o novo fazer coral", "a inclusão da performance cênica", "as alterações na interpretação e na vocalidade"; esta última, a autora acredita que as "alterações" acabaram sendo feitas para que os arranjos pudessem se readequar a esta nova proposta de escrita coral surgida do período de 1960 em diante.

Já em um artigo seu mais recente, Camargo e Ricciardi (2011, p. 163) afirmam que o termo tão comentado "Coro Cênico" pode ser entendido como uma "nova categoria coral", uma vez que após os anos 90 os grupos realizavam "encenações típicas de um show de entretenimento". Além disso, as movimentações de palco foram se tornando mais comuns entre estes grupos que "incorporaram a linguagem midiática com a criação de cenografia, figurino, iluminação, etc., confirmando a tendência de transformar o concerto em espetáculo".

Oliveira, já mencionado no início do texto, utiliza a expressão Coro Cênico na sua dissertação de mestrado. Como fundamentação para o termo, o autor explica que a formação do Coro Cênico se deu através da "incorporação da canção de massa no canto coral assim como a influência dos movimentos artísticos da década de 60". Assim como Bucci, Oliveira (1999, p. 13) defende que a questão do "hibridismo de linguagens" faz com que os grupos trabalhem com artes integradas como a dança, a expressão corporal e o teatro além do canto. "0 canto coral, antes uma expressão unidirecional, volta-se agora a uma concepção múltipla de expressão artística".

A descrição de um espetáculo de canto coral na dissertação de Souza nos revela a mesma necessidade de envolver em cena a música aliada ao teatro, figurinos, cenários e movimentação produzindo assim magia e encantamento nos espectadores. A pesquisa de Souza que também se aplica em trabalhos com corais, trata desta maneira de fazer música unindo corpo e o movimento à expressão vocal. Sobre a terminologia utilizada para definir este tipo de trabalho, a autora conclui que: 


\section{Coro Cênico: Conceito e Discussões}

Embora o termo coro cênico, bem como sua definição, não sejam consenso entre os artistas envolvidos com este tipo de proposta, é a ideia de um grupo que apresente este resultado artístico híbrido que nos interessa para o presente estudo. Assim, os corais que se propõem cênicos, seriam um espaço onde, necessariamente, encontraremos o trabalho com voz e corpo com um mesmo objetivo (SOUZA, 2011, p. 16).

\section{A Técnica do Cantor de Coro Cênico}

Corais que inserem artes como teatro e dança nos seus espetáculos devem ter a preocupação de trabalhar com uma técnica diferenciada nos ensaios. A técnica vocal aplicada ao repertório e ao movimento é um ponto fundamental dentro de um grupo que almeje trabalhar com outras artes além do canto. Aplicar exercícios relacionados ao repertório é uma maneira de fazer com que o mesmo não seja deixado de lado no momento do estudo da técnica. 0 grupo pode assim estar realizando juntamente com o exercício vocal certa movimentação que, aliada ao som, auxilia no aprendizado de circulação e posicionamento de palco. A execução da dinâmica e do fraseado, por exemplo, facilmente podem ser relacionadas com movimentos corporais dos cantores. É uma excelente forma de relacionar o trabalho corporal com o que deve ser cantado, evitando a repetição de vocalizes nos ensaios, auxiliando a memória com outros estímulos para fixar as canções. Sendo assim, o trabalho vocal estático e neutro não combina com a função do cantor em um coro cênico.

A repetição gerada por vocalizes sem maiores finalidades acaba gerando pouco interesse do grupo no início de suas atividades. Coelho (1994) enfatiza a importância na diversidade nos exercícios de aquecimento para evitar o tédio e o cansaço. A pesquisa de Muller (2009, p. 60) expõe entrevistas realizadas com quatro regentes de coro sobre as suas perspectivas na condução do trabalho com seus grupos. Pablo Trindade, um dos regentes entrevistados afirma que o aquecimento é feito, mas não a partir da repetição de sons: "O som é consequência da concentração deles" (informação verbal)'. 0 regente trabalha sempre com vocalizes criados no momento do ensaio, que tomam forma através da abertura de vozes ${ }^{8}$ inseridas aos poucos na mesma frase. Aos poucos, adiciona elementos de percussão corporal e movimentação. Outra maneira de aquecimento vocal que Trindade utiliza é a criação de melodias dos próprios cantores a partir de uma harmonia pré-estabelecida (improvisos): ele privilegia e valoriza o "pensar no por que da música e da arte em geral", e não somente o encontro coral como uma simples aquisição de técnicas. Na busca de caminhos mais atrativos e eficientes para a educação musical dos cantores, Zanetta sugere em seu trabalho que:

A partir das perspectivas de Brito (2001), Freire (2009; 2008) e Koellreutter (1997a, 1997b), visamos propor espaços de ensino-aprendizagem na educação musical em que os indivíduos sejam sujeitos ativos, dialoguem, questionem, usufruam de des-

7 Regente Pablo Trindade em entrevista a Muller. 0 regente está à frente do grupo Expresso 25, de Porto Alegre, RS.

$8 \quad$ Em um trabalho vocal os cantores não costumam cantar e dobrar a mesma melodia. Para tanto, existem os arranjos vocais que trabalham com a harmonia das canções abrindo normalmente quatro vozes diferentes que cantam simultaneamente. 


\section{Coro Cênico: Conceito e Discussões}

contração, espontaneidade e liberdade de criação, não considerando apenas aspectos técnicos musicais, mas a formação integral do indivíduo (ZANETTA, 2012, p. 24).

0 potencial criativo através da experimentação em exercícios de integração e expressão pode proporcionar ao cantor a descoberta do corpo, além da construção das emoções e das ações de um personagem proposto para uma determinada cena. Zanetta (2012) entende que para o aprendizado da técnica vocal deve-se propor o jogo teatral como ferramenta pedagógica, abordando assim as linguagens artísticas de forma interdisciplinar, sendo elas o trabalho do corpo, da voz e da emoção, buscando a "afinidade grupal" e evitando o constrangimento e falta de integração entre os cantores. Transformar situações é uma ação comum dentro do jogo, e os improvisos podem ser aliados dos cantores em momentos de tensão em cena nas mais diversas situações: "[...] o jogo teatral eleva a imaginação à recriação de novas percepções da realidade" (MARTINS, 2008, p. 26).

Januzelli em seu livro A aprendizagem do ator cita alguns dos principais teóricos da prática teatral que viabilizaram os processos de preparação do ator. Entre eles, Stanislavski defende que o processo criativo deve ser um "ato natural", onde o indivíduo vive as suas próprias experiências e utiliza "seu próprio material humano na criação do papel" (1986, p. 10). 0 teórico prefere eliminar máscaras, trejeitos, clichês e estereótipos: “0 ato natural é a preliminar que levará o ator a construir um papel vivo no palco" (1986, p. 10).

Como atividade livre, voluntária, espontânea, desligada de interesses materiais, o brincar implica confiança e concentração, envolve o corpo todo e a mente, e é acompanhado de um sentimento de tensão e de alegria capaz de absorver o ator de maneira intensa e total (JANUZELLI, 1986, p. 59).

A teoria de Stanislavski entende que o improviso e a imaginação devem ser minuciosamente elaborados além de serem erguidos solidamente "sobre uma base de fatos lógica e coerente: quando, onde, porquê, como [...]" (JANUZELLI, 1986, p. 17). Conforme Zanetta (2012, p. 35) os jogos teatrais além de auxiliarem na interpretação de modo geral, também auxiliam o cantor em aspectos técnicos relacionados diretamente à voz, como articulação, respiração, ressonância, afinação, ritmo e projeção vocal. Januzelli (1986, p. 59) acrescenta que pelo fato do jogo fazer parte de uma "zona neutra", permite desenvolver no ator requisitos fundamentais para a criação no teatro como "ritmo, harmonia, mudança, alternância, contraste, clímax". Januzelli cita Stanislavski no que diz respeito ao treino de dicção e canto e sugere algumas práticas, desenvolvendo:

[...] a sensação das palavras; trocar o lugar das pausas e das acentuações; articular lábios, língua e maxilares; exercícios de respiração e vibração das notas sustentadas; exercitar pausas (psicológicas, gramaticais ou lógicas), acentuação (para tornar a palavra expressiva); bocejar, mugir (JANUZELLI, 1986, p. 16).

A norte-americana Viola Spolin (1906-1994), profissional que direcionou seus trabalhos 


\section{Coro Cênico: Conceito e Discussões}

e pesquisas ao teatro-educação explora os jogos teatrais, que desenvolvem noções de personagem, de ação e espaços cênicos. A autora acredita que estes jogos são o ponto de partida para a criação de pequenas cenas, e enumera três pontos (ela assegura serem essenciais de todo o jogo teatral): "foco, instrução e avaliação" (SPOLIN, 2008, p. 32). A partir de um "foco" apresentado pelo orientador, se faz o movimento do jogo. A energia é gerada por meio da permanência do "foco", mas isto não quer dizer que o "foco" é o objetivo do jogo. "Todos se tornam parceiros ao convergir para o mesmo problema a partir de diferentes pontos de vista" (SPOLIN, 2008, p. 32).

0 jogo teatral, constituído de um problema a ser solucionado pela equipe precisa que o grupo mantenha o "foco" e encontre uma solução. Para tal, Spolin sugere o princípio da "instrução": "A instrução deve guiar os jogadores em direção ao foco, gerando interação, movimento e transformação" (2008, p. 33). 0 último ponto enumerado por Spolin é a "avaliação". Neste caso, a avaliação não é uma forma de julgamento ou crítica, mas tem a função de reestabelecer o "foco". Sendo assim, os grupos "lidam com o problema que o foco propõe e indagam se o problema foi solucionado" (SPOLIN, 2008, p. 34).

Inúmeros jogos estão à disposição do leitor no livro de Spolin, que traz objetivos variados para cada um deles. Alguns objetivos desenvolvem os sentidos da visão; audição; memória; emoção; improvisação; imaginação; dramatização; concentração; comunicação verbal e não verbal; observação crítica; ritmo; exploração sonora; definem e constroem personagens, além de trabalhar o grupo, fundamental no caso de coros e grupos vocais cênicos.

\section{Considerações finais}

Vemos atualmente em diversos grupos corais uma forma mais tradicional de fazer música, onde normalmente focam seus trabalhos no canto em grupo, na sonoridade e se apresentam todos em lugares fixos, divididos organizadamente em naipes de soprano, contralto, tenor e baixo, entrando no palco com pastas que auxiliam na leitura do repertório e com a presença do regente comandando o coro. Pelos aspectos discutidos nesta pesquisa, entende-se que neste estilo de canto coral tradicional não se encontram as peculiaridades que grupos de Coro Cênico apresentam. Em relação ao trabalho de coros tradicionais e coros cênicos, percebe-se um diálogo maior e coerência de ideias entre regentes destes últimos e profissionais de outras áreas como diretores de teatro, coreógrafos, figurinistas, iluminadores, o que reforça o perfil de um trabalho integrado para a conquista de uma realização musical com utilização de linguagens de apoio.

A renovação do canto coral teve como consequência uma mudança dentro da concepção de apresentação para uma concepção de espetáculo. Em decorrência disso e da busca por alternativas tanto no aspecto visual quanto no aspecto sonoro, surgiu 0 termo Coro Cênico para designar grupos que buscavam viabilizar uma nova modalidade de canto coral, quebrando a neutralidade dos cantores no palco e fugindo dos padrões tradicionais pré-estabelecidos.

Deste modo, entendo que a expressão "Coro Cênico" pode ser designada para retratar 


\section{Coro Cênico: Conceito e Discussões}

os grupos que atualmente têm baseado seus trabalhos em propostas que visam abarcar as artes de forma integrada, procurando desenvolvê-las equilibradamente. Sendo assim, além do canto coral, passam a fazer parte do escopo de interesse desses grupos, a expressão corporal, o teatro e a dança, aliados a alguns trabalhos de percussão corporal. A técnica vocal aliada ao repertório e a jogos teatrais mostra ser de fundamental importância dentro desta nova modalidade que exige do cantor um conhecimento de maior profundidade na interpretação musical e maior consciência de sua presença cênica. Alguns grupos de Coro Cênico também encontram no figurino e no cenário a sua construção de identidade na montagem de espetáculos diferenciados da roupagem tradicional utilizada por coros que não trabalham com este propósito. 


\section{Coro Cênico: Conceito e Discussões}

Referências

> BOSSA NOSSA. Site oficial do grupo. Ribeirão Preto, SP, s/a. Disponível em: <http://www. bossanossa.org/index.htmlı. Acesso em 24 fev. 2013.

> BUCCl, Magno. Coro Cênico: Breves Reflexões a Partir de uma Prática. 2007. Disponível em: 〈http://www.bossanossa.org/MAGNO/BREVES\%20-\%20REVISAD0.pdf〉. Acesso em: 18 jan. 2013.

$>$

. Nem todo coro é cênico e nem todo "coro cênico" é cênico: Breves reflexões a partir de uma prática II. 2010. Disponível em: 〈http://www.bossanossa.org/MAGNO/ Nem\%2otodo\%2ocoro.pdf $>$. Acesso em: 18 jan. 2013.

> CAMARG0, Cristina Moura Emboaba da Costa Julião de. Criação e Arranjo: Modelos de Repertório para o Canto Coral no Brasil. Dissertação de Mestrado do Departamento de Música da Escola de Comunicações e Artes da Universidade de São Paulo. São Paulo, 2010. Disponivel em: 〈http://www.teses.usp.br/teses/disponiveis/27/27157/tde04112010-144243/es.php>. Acesso em: 14 set. 2012.

$>$

Cristina Moura Emboaba da Costa Julião de; RICCIARDI, Rubens Russomanno. Será que aquilo deu nisso? - A deteriorização do canto e da composição coral no Brasil desde a inserção de arranjos de canções da indústria da cultura. Revista Trama Indisciplinar - v.2 - n. 2 - 2011. Disponível em: <http://editorarevistas.mackenzie.br/index.php/ tint/article/view/4428>. Acesso em: 05 out. 2012.

> CAVALCANTI, Nestor de Hollanda. Às Voltas com o Canto Coral. In: LAKSCHEVITZ, Eduardo (Org.). Ensaios: olhares sobre a música coral brasileira. Rio de Janeiro: Centro de estudos de Música Coral / Oficina Coral, 2006. Disponível em: 〈http://www.funarte. gov.br/projetocoral/wp-content/uploads/2012/07/LivroEnsaios_Ebook_28-08.pdf>. Acesso em: 28 out. 2012.

$>$ COBRAS A LAGARTOS. Coral da Cultura Inglesa. "Melhor Trabalho Criativo do MPB Shell 81". Festival de MPB Shell de 1981. Disponivel em: 〈http://www.youtube.com/watch?V=UdNrFlb7Uko>. Acesso em 13 out. 2012.

> COELHO, Helena Wöhl. Técnica vocal para coros. São Leopoldo, RS: Sinodal, 1994.

> JANUZELLI, Antônio. A aprendizagem do ator. São Paulo: Ática, 1986.

> KOHLER, Eusébio Nicolau. Contracultura e Movimento Coral Brasileiro. Monografia de Pós Graduação. Escola de Música e Belas Artes do Paraná, Curitiba: EMBAP, 1997.

> MARTINS, Janaína Träsel. Os princípios da ressonância vocal na ludicidade de jogos de corpo-voz para a formação do ator. Tese - Universidade Federal da Bahia, Salvador, 2008.

$>$ MULLER, Cristiane. 0 desenvolvimento de atividades em grupos vocais na perspectiva de quatro regentes. Trabalho de conclusão de curso. Licenciatura em Música da Universidade do Estado de Santa Catarina. UDESC, 2009. Disponível em: 〈http://www. pergamumweb.udesc.br/dados-bu/000000/00000000000F/00000FDo.pdf〉. Acesso em: 29 


\section{Coro Cênico: Conceito e Discussões}

ago. 2012.

$>$ OLIVEIRA, Sérgio Alberto de. Coro-cênico: uma nova poética coral no Brasil. Dissertação do Curso de Mestrado em Artes do Instituto de Artes da UNICAMP. Campinas, 1999. Disponível em: 〈http://www.bibliotecadigital.unicamp.br/document/?code=000210758 . Acesso em: 04 set. 2012.

> OVERMUNDO. Encontro Brasileiro de Coro Cênico em Ribeirão. Publicado em 07/10/2011. Disponivel em: 〈http://www.overmundo.com.br/overblog/encontro-brasileiro-de-coro-cenico-em-ribeira0〉. Acesso em 01 jul. 2013.

> REVIDE, Guia Cultural. V Encontro Brasileiro de Coro Cênico. Publicado em 14/09/2011. Disponível em: 〈http://www.revide.com.br/guia-cultural/v-encontro-brasileiro-de-coro-cenico/>. Acesso em: 01 jul. 2013.

> SoUZA, Simone Santos. Corpo-Voz em Contexto Coletivo: Ações Vocais Formativas no Canto Coral. Dissertação de Mestrado do Curso de Pós Graduação em Educação Brasileira, da Universidade Federal do Ceará. Fortaleza, 2011. Disponível em: 〈http://www. repositorio.ufc.br:8080/ri/bitstream/123456789/3504/1/2011_DIS_SSSOUSA.pdf〉. Acesso em: 27 ago. 2012.

> SPOLIN, Viola. Jogos teatrais para a sala de aula: um manual para o professor. Tradução: Ingrid Dormien. São Paulo: Perspectiva, 2008.

> V ENCONTRO BRASILEIRO DE CORO CÊNICO. Ribeirão Preto, SP, 2011. Disponível em: <http://www.bossanossa.org/V\%20ENCONTRO/PROGRAMACA0.html〉. Acesso em 25 fev. 2013.

> ZANATTA, Silvia Helena de Souza. Corpo-Voz-Movimento: Uma nova abordagem expressiva no canto coral. Trabalho de Conclusão de Curso de Especialização em Pedagogia da Arte de Pós-Graduação em Educação da Faculdade de Educação da Universidade Federal do Rio Grande do Sul. Porto Alegre, 2008. Disponível em: < http://www.lume.ufrgs.br/ handle/10183/15670>. Acesso em 18 nov. 2012.

> ZANETTA, Camila Costa. Jogos teatrais como colaboradores no processo pedagógico do canto. 2012. TCC (graduação)-Licenciatura em Música. UDESC. Florianópolis, 2012. Disponível em: < http://www.pergamumweb.udesc.br/dados-bu/000000/000000000017/00001763. pdf $>$. Acesso em: 07 abr. 2013. 
Coro Cênico: Conceito e Discussões

Cristiane Muller, Aluna do PPGMUS-UDESC-Florianópolis/SC. Área: musicologia/etnomusicologia crispassarim@hotmail.com

Luiz Henrique Fiaminghi, Professor doutor do PPGMUS-UDESC-Florianópolis/SC. Área: musicologia/etnomusicologia

Ihfiaminghi@yahoo.com.br 